\title{
Unequal contribution of native South African phylogeographic lineages to the invasion of the African clawed frog, Xenopus laevis, in Europe
}

Charlotte De Busschere, Julien Courant, Anthony Herrel, Rui Rebelo, Dennis Rödder, G. John Measey, Thierry Backeljau

Due to both deliberate and accidental introductions, invasive African Clawed Frog (Xenopus laevis) populations have become established worldwide. In this study, we investigate the geographic origins of invasive $X$. laevis populations in France and Portugal using the phylogeographic structure of $X$. laevis in its native South African range. Our results show that native phylogeographic lineages have contributed differently to invasive European $X$. laevis populations. In Portugal, genetic and historical data suggest a single colonization event involving a small number of individuals from the south-western Cape region in South Africa. In contrast, French invasive $X$. laevis encompass two distinct native phylogeographic lineages, i.e. one from the south-western Cape region and one from the northern regions of South Africa. The French $X$. laevis population is the first example of a $X$. laevis invasion involving multiple lineages. Moreover, the lack of population structure based on nDNA suggests a potential role for admixture within the invasive French population. 
1 Title: Unequal contribution of native South African phylogeographic lineages to the 2 invasion of the African clawed frog, Xenopus laevis, in Europe

3 Authors: Charlotte De Busschere ${ }^{1}$, Julien Courant ${ }^{2}$, Anthony Herrel $^{2}$, Rui Rebelo ${ }^{3}$, Dennis

4 Rödder ${ }^{4}$, G. John Measey ${ }^{5}$, Thierry Backeljau ${ }^{1,6}$

5 Affiliations:

$6{ }^{1}$ Royal Belgian Institute of Natural Sciences, OD Taxonomy and Phylogeny, Vautierstraat 29,

71000 Brussels, Belgium.

$8 \quad{ }^{2}$ UMR 7179 C.N.R.S./M.N.H.N., Département d'Ecologie et de Gestion de la Biodiversité, 57 rue

9 Cuvier, Case postal 55, 75231, Paris Cedex 5, France.

10 글 Fundação da Faculdade de Ciencias da Universidade de Lisboa, Lisbon, Portugal.

$11{ }^{4}$ Herpetological Department, Zoologisches Forschungsmuseum Alexander Koenig (ZFMK),

12 Adenauerallee 160, 53113, Bonn, Germany.

$13{ }^{5}$ Centre of Invasive Biology, Department of Botany and Zoology, University of Stellenbosch, 14 Stellenbosch, South Africa.

$15{ }^{6}$ Evolutionary Ecology Group, University of Antwerp, Groenenborgerlaan 171, 2020 Antwerp, 16 Belgium

17 Correspondence: Charlotte De Busschere, Royal Belgian Institute of Natural Sciences, OD

18 Taxonomy and Phylogeny, Vautierstraat 29, 1000 Brussels, Belgium.

19 Charlotte.debusschere@gmail.com 
20 Abstract

21 Due to both deliberate and accidental introductions, invasive African Clawed Frog (Xenopus

22 laevis) populations have become established worldwide. In this study, we investigate the

23 geographic origins of invasive $X$. laevis populations in France and Portugal using the

24 phylogeographic structure of $X$. laevis in its native South African range. In total 80 individuals

25 from the whole area known to be invaded in France and Portugal were analysed for two

26 mitochondrial and three nuclear genes allowing a comparison with 185 specimens from the

27 native range. Our results show that native phylogeographic lineages have contributed differently

28 to invasive European $X$. laevis populations. In Portugal, genetic and historical data suggest a

29 single colonization event involving a small number of individuals from the south-western Cape

30 region in South Africa. In contrast, French invasive $X$. laevis encompass two distinct native

31 phylogeographic lineages, i.e. one from the south-western Cape region and one from the northern

32 regions of South Africa. The French $X$. laevis population is the first example of a $X$. laevis

33 invasion involving multiple lineages. Moreover, the lack of population structure based on nuclear

34 DNA suggests a potential role for admixture within the invasive French population. 


\section{Introduction}

Reconstructing the invasion history and dynamics of invasive species is crucial for understanding biological invasions and for developing appropriate management strategies (Sakai et al., 2001; Lee \& Gelembiuk, 2008; Prentis et al., 2009). Moreover, exploring patterns of population genetic variation and evolutionary processes may be key to infer the invasive potential of invasive alien species (Sakai et al., 2001; Lee \& Gelembiuk, 2008). In this study, we focus on the African clawed frog, Xenopus laevis (Daudin, 1802), which is indigenous to Southern Africa, including South Africa up to Malawi (i.e. X. laevis sensu stricto (Furman et al., 2015)). Due to deliberate and accidental introductions from laboratories and pet suppliers, invasive $X$. laevis populations have become established in Asia, Europe, North America and South America (Tinsley \& McCoid, 1996; Lobos \& Measey, 2002; Crayon, 2005; Fouquet \& Measey, 2006; Faraone et al., 2008; Measey et al., 2012; Peralta-García, Valdez-Villavicencio \& Galina-Tessaro, 2014). Invasive $X$. laevis populations have negative impacts on local biota by reducing the occurrence of reproduction (Lillo, Faraone \& Lo Valvo, 2010) and increasing predation pressures on native prey organisms (Lafferty \& Page, 1997; Faraone et al., 2008; Measey et al., 2015). Lobos and Measey (2002) also suggested that $X$. laevis might have indirect impacts on the aquatic system such as increasing water turbidity and nutrient release. Finally, the spread of Batrachochytrium dendrobatis which causes the amphibian skin disease chytridiomycosis and negatively impacts amphibian populations (Berger et al., 1998; Lips et al., 2006; Skerratt et al., 2007; Voyles et al., 2009; Crawford, Lips \& Bermingham, 2010), has been linked to invasive amphibian species such as $X$. laevis which are often asymptotic carriers (Weldon et al., 2004), however this link has yet to be proven. Measey et al. (2012) suggested that the global potential invasiveness of $X$. laevis has been severely underestimated and that it is likely that $X$. laevis will expand its present colonized area. For example in Europe, introduced $X$. laevis populations are currently established in France (Fouquet, 2001), Portugal (Rebelo et al., 2010) and Italy (Sicily) (Lillo et al., 2005), though the predicted suitable climate space for $X$. laevis covers over one million $\mathrm{km}^{2}$ making this a species of European concern (Measey et al., 2012).

Within its native range, $X$. laevis has a wide geographical distribution in which it occupies a variety of natural, as well as manmade waterbodies (Measey, 2004). Native X. laevis populations are distributed from winter rainfall regions in the south-western Cape region to summer rainfall regions in the north; and from sea level to nearly $3000 \mathrm{~m}$ in Lesotho (Measey, 2004). 
66 Furthermore, several physiological and behavioural traits enable $X$. laevis to cope with,

67 dehydration, high levels of salinity, starvation and anoxic conditions (reviewed in Measey et al. 2012). Throughout the native range of $X$. laevis significant population differentiation has been observed based on both mitochondrial (mtDNA) and nuclear DNA (nDNA) sequences (Grohovaz, Harley \& Fabian, 1996; Measey \& Channing, 2003; Du Preez et al., 2009; Furman et al., 2015). As such, Furman et al. (2015) identified four phylogeographic lineages within South Africa based on mtDNA and nDNA: 1) south-western Cape (SA1-SA2), 2) Beaufort West (SA4), 3) Niewoudtville (SA7) and 4) northern South Africa (Kimberley, Victoria West, Potchefstroom, SA5) (Fig. 1). The latter two clades are geographically separated by the coastal regions due to the Great Escarpment i.e. a plateau edge running parallel with the South African coast and separating the inland plateau from the coastal plains (Grab, 2010). An admixture zone was observed around Laingsburg (SA3) between south-western Cape (SA1-SA2) and Beaufort West (SA4). Laingsburg (SA3) and Beaufort West (SA4) are both located within the lowland part of the Great Karoo (700 - $800 \mathrm{~m}$ above sea level) which is separated from the south-western Cape (SA1-SA2) by the Cape Fold Mountains (Du Preez et al., 2009; Furman et al., 2015) and from the north by the Great Escarpment (Fig. 1). Another admixture zone was suggested between Niewoudtville (SA7) and the south-western Cape populations (SA1) around Vredendal (Measey $\&$ Channing, 2003). In its native range $X$. laevis also displays substantial phenotypic population differentiation. Du Preez et al. (2009), for example, showed that male X. laevis from south of the Cape Fold Mountains were longer and heavier than males from north of the Cape Fold Mountains.

Given its wide native geographical and ecological ranges and high population genetic diversity, it is important to identify the source areas and population(s) of invasive X. laevis populations if one aims to understand the invasion history and invasive potential of this species (Sakai et al., 2001; Lee, 2002; Dlugosch \& Parker, 2008; D'Amen, Zimmermann \& Pearman, 2013). The origin of invasive $X$. laevis populations in Sicily and Chile has already been explored using DNA markers (Lillo et al., 2013; Lobos et al., 2014). Similarly, the origin of specimens from animal suppliers i.e. Xenopus-1 Inc. (Missouri, USA) and Xenopus Express (Florida, USA), has been assessed (Du Preez et al., 2009). These studies support the assumption that export of X. laevis specimens for laboratory use mainly stemmed from the south-western Cape region in South Africa (Tinsley \& McCoid, 1996; Weldon, De Villiers \& Du Preez, 2007), although other source 
97 areas cannot be excluded, especially for older introduced stocks (Du Preez et al. 2009; L. van 98 Sittert and J. Measey, unpublished data).

99 The present paper aims to unravel to which extent single or multiple native phylogeographic

100 lineages have contributed to the invasive populations in France and Portugal by comparing 101 mtDNA and nDNA data sampled across the invaded, as well as the native range. In France, it is

102

103 assumed that $X$. laevis was introduced at Bouillé-Saint-Paul (Deux Sèvres) from a nearby breeding facility where $X$. laevis was bred from the 1950s until 1996 (Fouquet, 2001; Fouquet \& Measey, 2006). From that breeding facility $X$. laevis may have escaped repeatedly and was probably released when the facility was definitively closed in 1996 (Measey et al., 2012). Currently, French $X$. laevis populations occupy an area of approximately $200 \mathrm{~km}^{2}$ near the city of Saumur (Maine-et-Loire) (Fig. 1). The introduction of $X$. laevis in Portugal is assumed to be accidental, caused in 1979 by the inundation of a basement of a research institute at Oeiras along river Laje, about $20 \mathrm{~km}$ west of Lisbon (Rebelo et al., 2010; Measey et al., 2012). Nowadays, several populations are found in two tributaries of river Tagus, i.e. river Laje and river Barcarena (Fig. 1) (Rebelo et al., 2010).

\section{Methods}

\section{Taxon sampling}

In total 80 individuals from 32 localities, covering the known area invaded by $X$. laevis in France (FR) and Portugal (PT) were captured. For comparison with previous work of Lillo et al. (2013) we included two specimens from Sicily (IT, provided by Francesco Lillo). Within the native range of $X$. laevis, 21 specimens were sampled. Seven specimens came from two localities in the south-western Cape (SA1) i.e. Cape of Good Hope nature reserve and a single dam at Jonkershoek, the location from which animals were shipped for international trade from the 1940s to 1970s (L. van Sittert and J. Measey, unpublished data). 14 specimens came from five localities around Rooikrantz Dam near the historical Pirie hatchery nearby King Williams Town, Eastern Cape (SA6) (L. van Sittert and J. Measey, unpublished data ). These new data were supplemented by data on 164 South African specimens available on GenBank. One individual of Xenopus gilli Rose \& Hewitt, 1927 was sampled near Kleinmond (South Africa). Based on Furman et al. (2015), sampling localities in South Africa were grouped into seven geographical 
126 regions: SA1: south-western Cape, south-west of the Cape Fold Mountains up to De Doorns;

127 SA2: Cape, Hoekwil \& Tsitsikamma region; SA3: Cape, Laingsburg; SA4: Cape, Beaufort West;

128 SA5: northern South Africa (Kimberley, Victoria West, Potchefstroom); SA6: Cape, Rooikrantz

129 Dam; SA7: Nieuwoudtville (Fig. 1). All specimen data with full locality information are

130 provided in Online Resource 1. Animals from the Portuguese invasive population were captured

131 under the permit $n^{\circ}$ 570/2014/CAPT from Instituto da Conservação da Natureza e das Florestas,

132 in the scope of the "Plano de erradicação de Xenopus laevis nas ribeiras do Concelho de Oeiras".

133 Animals from the native South-African populations were sampled under the permits 0056-

134 AAA007-00092 (CapeNature, SA1) and CRO 109/13CR (Eastern Cape, SA6) provided by the

135 Department of Economic Development, Environmental Affairs and Tourism and with ethics

136 approval from the Research Ethics Committee: Animal Care and Use (protocol number: SU-

137 ACUD14-00028).

138

DNA amplification and sequencing

140

Invasive specimens were euthanized with a lethal injection of sodium pentobarbital. Muscle tissue was dissected from invasive specimens, while native wild caught specimens were toeclipped to obtain tissue samples. Genomic DNA was extracted by means of a NucleoSpin ${ }^{\circledR}$ tissue kit (Macherey-Nagel, Düren) according to the manufacturer's protocol. Five genomic DNA fragments (circa (ca.) 2040 bp) representing two mitochondrial and three nuclear gene fragments were amplified using PCR. These genes were selected in order to enable comparison with previously published work on native (Measey \& Channing, 2003; Du Preez et al., 2009; Bewick, Anderson \& Evans, 2011; Furman et al., 2015) and invasive X. laevis specimens (Lillo et al., 2013; Lobos et al., 2014). Fragments of the mitochondrial cytochrome b gene (Cytb; ca. $280 \mathrm{bp})$ and $16 \mathrm{~S}$ ribosomal DNA (16S; ca. $800 \mathrm{bp}$ ) were amplified and sequenced with the primer pairs Cytb I /Cytb II and 16Sc-L/16Sd-H (Kessing et al., 1989; Evans et al., 2003). Fragments of the nuclear protein coding genes arginine methyltransferase 6 (Prmt6; ca. 666 bp), androgen receptor isoform $\alpha$ (AR; ca. 402 bp) and microtubule associated serine/threonine kinase-like protein (Mastl; ca. 539 bp) were amplified and sequenced with the primer pairs Exon4_for1/Exon4_rev2, XLAR_for_40/XLAR_rev_431 and Exon13_fora/Exon13_reva (Bewick, Anderson \& Evans, 2011). The nuclear primer pairs are assumed to be paralog- 
156 specific, hence only amplifying one pair of alleles (see (Bewick, Anderson \& Evans, 2011)).

157 PCR amplifications were run with the conditions reported in Online Resource 3. PCR products

158

159

160

161

162 were purified with FastAP TM thermosensitive alkaline phosphatase in combination with exonuclease I and subsequently sequenced in both directions. Nucleotide sequences were assembled and edited in CodonCode Aligner (CodonCode Corporation, Dedham, MA, USA).

They were aligned together with corresponding well-documented sequences of South African $X$. laevis available from GenBank using the ClustalW algorithm (Thompson, Higgins \& Gibson, 1994) in $M E G A$ v. 6 (Tamura et al. 2013). For comparison, the two Cytb haplotypes found by Lobos et al. (2014) in Chilean (CL) invasive $X$. laevis populations were included in the Cytb alignment. Cytb and 16S gene fragments obtained by Lillo et al. (2013) were not included in the current alignments as they only partially overlapped due to the use of different primers. Nuclear sequences were converted into haplotypes using the PHASE algorithm (Stephens, Smith \& Donnelly, 2001; Stephens \& Donnelly, 2003) implemented in DnaSP v. 5 (Librado and Rozas 2009). All new sequence data were deposited in Genbank (accession numbers in Online Resource 1).

Genetic diversity

The following indices of genetic diversity were estimated using DnaSP v. 5 (Librado \& Rozas, 2009): numbers of different haplotypes (h), the number of segregating sites (S), nucleotide diversity $(\pi$, i.e. the average number of nucleotide differences per site between two sequences) and haplotype/allelic diversity $(\mathrm{Hd}$, i.e. the probability that two haplotypes drawn uniformly at random from a population are not the same).

mtDNA analysis

Phylogenetic relationships among invasive and native $X$. laevis mtDNA sequences were reconstructed with Bayesian inference (BI) and Maximum Parsimony (MP). Three alignments were created: two separate Cytb and 16S alignments including only unique alleles and a concatenated Cytb-16S alignment including only unique haplotypes. In all analyses, $X$. gilli was used as outgroup. Parsimony informative sites were calculated with DnaSP v. 5 (Librado \& Rozas, 2009). BI analyses were performed using MrBayes v. 3.2.4 (Ronquist \& Huelsenbeck, 2003). Cytb, 16S and Cytb-16S alignments were analysed under a general time reversible (GTR) 
185 model with all model parameters estimated from the data and a proportion of invariant sites $(+\mathrm{I})$

186 as selected by jModeltest v. 2.1.7 (Posada, 2008). BI analyses were run with two different

187 Metropolis-coupled Markov chains for 10 million generations with sampling every 1000th

188 generation. The average standard deviations of split frequencies, the potential scale reduction

189 factors and the plots of likelihood versus generation were evaluated to ensure convergence based

190 on the log file and using Tracer v1.6 (Rambaut, Drummond \& Suchard, 2013). 25\% of the trees

191 were discarded as burn-in and posterior probabilities were calculated for each split from the

192 remaining set of trees. MP trees were estimated with a neighbour joining tree as starting tree

193 using the Phangorn package (Schliep, 2011) in R 3.1.1 (R Core Team, 2014). A set of most-

194 parsimonious trees was generated using the parsimony ratchet (Nixon, 1999) with nearest

195 neighbour interchange rearrangement, 10000 ratchet iterations and up to maximum 10 rounds.

196 Parsimony bootstrap values were obtained with 1000 bootstrap replicates using the

197 bootstrap.phyDat function in R 3.1.1. All topologies were visualized and edited in respectively

198 Figtree v. 1.4.2 (Rambaut, 2006) and TreeGraph2 v. 2.4.0-456 beta (Stöver \& Müller, 2010).

199 Differentiation between native geographical areas and invaded regions was quantified using

200 pairwise $F s t$ values computed based upon nucleotide pairwise distances and tested for

201 significance with 999 permutations using Arlequin v. 3.5.3.1 (Excoffier \& Lischer, 2010). The

202 population comparison was done solely for the $16 \mathrm{~S}$ alignment as this dataset included sequences

203 of most individuals $(\mathrm{n}=179)$ and representatives of all populations.

204 Autosomal analysis

205 The minimum number of recombination events estimated in DnaSP v.5 (Hudson \& Kaplan,

206 1985; Librado \& Rozas, 2009) yielded one, five and six events for AR, Mastl and Prmt6

207 respectively. Hence, to investigate the intraspecific relationships among the different alleles from

208 each of these nuclear loci and their distribution among invasive and native populations, median-

209 joining networks (MJN) (Bandelt et al. 1999) were constructed in PopART v. 1.7.2 (PopART,

210 2015) for each gene separately. MJN depicts an allele network showing the history of mutations

211 that have occurred among the different alleles of the sampled sequences (Mardulyn, 2012).

212 Furthermore, pairwise $F s t$ values were computed based on the allele frequencies to unravel to

213 which extent alleles are differently fixed among populations. More precisely, two populations

214 might share identical alleles however differ in the corresponding allele frequencies. Native 
215 populations were defined based upon the geographical regions mentioned in 'Taxon sampling'.

216 Individuals from France and Portugal respectively were treated as two populations. Pairwise Fst

217 values were computed from the allele frequencies with 999 permutations to generate the

218 probability that a random value would be greater than or equal to the observed data using

219 GenAlEx v. 6.5 (Peakall and Smouse 2012). Individuals with missing data for more than one

220 gene were excluded from the analysis. In order to visualize population differentiation, the

221 pairwise $F s t$ matrix was subsequently used as a distance matrix for a principal coordinates

222 analysis (PCoA) in GenAlEx v. 6.5.

\section{Results}

mtDNA

225

226

227

228

229

230

231

232

233

234

235

236

237

238

239

240

241

242

243

Mitochondrial alignments were constructed for Cytb and 16S involving 101 and 181 individuals respectively. The concatenated Cytb-16S alignment involved 64 individuals. None of the alignments showed gaps. The Cytb alignment involved16 unique alleles of $X$. laevis with 42 variable positions of which 34 were parsimony informative. No Cytb sequences were obtained of specimens from the regions SA2, SA3 and SA4. In contrast, all geographic regions were represented in the $16 \mathrm{~S}$ alignment, which involved 15 alleles of $X$. laevis with 25 variable positions of which 17 were parsimony informative. The concatenated Cytb-16S alignment involved seven unique $X$. laevis haplotypes with 43 variable positions of which 39 were parsimony informative (Online Resource 2). The concatenated alignment comprised only specimens from the invaded regions PT, IT and FR and the native regions SA1 and SA6. The BI and MP trees for Cytb and 16S are shown in Fig. 2. These analyses all resolved consistently three well-supported clades comprising $X$. laevis alleles from the geographic regions 1) SA5, SA6 and FR, 2) SA7 and 3) SA1, PT, FR, IT. Additionally, the phylogeny generated from the 16S data strongly supported 1) SA1, SA2, SA3, FR, PT and IT and 2) SA3-SA4 as wellsupported X. laevis clades. BI and MP trees for the concatenated data (Online Resource 2) showed two highly supported clades comprising haplotypes from 1) FR, PT, IT, SA1 and 2) FR and SA6. Pairwise population Fst values among all geographic regions based on $16 \mathrm{~S}$ were significant except among 1) SA1, SA2 and PT, 2) SA5 and SA6 and among 3) FR and SA6 (Online Resource 4). 
244 nDNA

245 AR sequences $(n=121)$ showed eight polymorphic positions of which seven revealed

246 heterozygous genotypes. The maximum number of heterozygous positions observed within a

247 single AR sequence was three but that was only observed in two individuals. The two most

248 frequent AR alleles i.e. hap_1 and hap_2 differed by two nonsynonymous substitutions. The

249 Mastl alignment $(\mathrm{n}=180)$ showed 37 polymorphic positions and 108 individuals were

250 heterozygous at $3 \pm 2$ positions on average. The Prmt6 alignment $(n=176)$ showed 20

251 polymorphic positions and 107 individuals were heterozygous at on average $2 \pm 1$ positions.

252 MJN revealed high allelic diversity at Mast1 and Prmt6 and low allelic diversity at AR (Table 1).

253 In the MJN, the most frequent alleles were often found in different geographical regions (Fig. 4).

254 When combining the allelic frequency information of the three nDNA genes, pairwise population

255 Fst values among all geographic regions were significant except between SA5 and SA6 (Online

256 Resource 5). The first two PCoA-axes explained 75\% of the total variance from the pairwise Fst

257 values. There was a clear separation among SA7 and the remnant populations along the first

258 PCoA axis (explaining $28 \%$ of the total variance). Negative values along the second PCoA axis

259 (explaining $47 \%$ of the total variance) were linked to the northernmost up to the north-eastern

260 native populations (SA4-SA7), while positive values were linked to the invasive (Fr, PT) and

261 southernmost native populations (SA1-SA3)(Fig. 3). Native populations SA5 and SA6 clustered

262 together (Fig. 3).

263 South Africa

264 Haplotype diversity of nDNA and mtDNA within the native range of $X$. laevis was on average

$2650.60 \pm 0.20$ and $0.45 \pm 0.18$ respectively. Mitochondrial nucleotide diversity within the native

266 regions was either rather low $(\pi \leq 0.0016$ : SA1, SA2, SA4, SA6) or high $(\pi \geq 0.0059$ : SA3, SA5,

267 SA7). As mentioned previously, mtDNA and nDNA variation was geographically structured

268 within South Africa (Fig. 2, Online Resource 4 and 5) (Furman et al., 2015). The monophyly of

269 the sequences from northern South African regions (SA5) and the newly sampled sites at

270 Rooikrantz Dam in the Eastern Cape (SA6) was consistently strongly supported by both Cytb

271 and 16S (Fig. 2). Furthermore, the pairwise population Fst values based on nDNA and on 16S

272 separately were not significant between these two regions (Online Resource 4 and 5). 
273 Portugal

274 Nucleotide and haplotype diversities in Portugal were extremely low for all markers $(0 \leq \pi<$ $2750.00105,0 \leq \mathrm{Hd}<0.294$, Table 1$)$, except for Prmt6 $(\pi=0.00213, \mathrm{Hd}=0.605$, Table 1$)$. Only 276 two alleles were exclusively found in Portugal, viz. one for Cytb (hap_11) and one for Prmt6 277 (hap_27). The concatenated Cytb-16S haplotype (hap_11_2) was only found in Portugal. All 278 other mtDNA and nDNA alleles occurred also within native South African populations. More 279 precisely, identical mtDNA was found in X. laevis populations from the south-western Cape SA1 280 (Cytb: hap_12) and from the Cape regions SA1-SA3 (16S: hap_2). Identical AR, Prmt6 and 281 Mastl alleles were found in respectively the following native regions 1) SA1-SA3, 2) SA1-SA4 and SA7 and 3) SA1-SA7. Pairwise Fst values based on 16S were not significant among Portugal and native regions SA1 and SA2 (Online Resource 4). PCoA and MJN revealed that nuclear allele frequencies within Portugal were most similar to those of native region SA1 (Fig 3, Online Resource 5). The mean Portuguese nucleotide diversity $(\pi=0.0007 \pm 0.0009)$ across all loci was much lower than in native populations $(\pi=0.0039 \pm 0.0035)$. Similarly, the mean Portuguese haplotype diversity $(\mathrm{Hd}=0.191 \pm 0.261)$ across all loci was lower than in the native populations $(\mathrm{Hd}=0.558 \pm 0.323)$.

France

Two distinct alleles were observed in the introduced French population for both Cytb and $16 \mathrm{~S}$ (Table 1, Fig. 2). Moreover, these alleles were highly similar or identical to alleles found in two geographically non-overlapping native regions in South Africa, i.e. the northern South Africa and Rooikrantz Dam region (SA5-SA6) and the south-western Cape region (SA1-SA3) (Fig. 2). The most abundant Cytb allele in France (i.e. hap_16; 86 \% of specimens) was very similar to Cytb sequences in northern South Africa and Rooikrantz Dam populations (SA5-SA6) with on average four nucleotide differences (Fig. 2). Similarly, 86\% of the French individuals had a 16S allele (i.e. hap_12) identical to a $16 \mathrm{~S}$ sequence only found in northern South Africa and Rooikrantz Dam region (SA5-SA6)(Fig. 2). The concatenated Cytb-16S dataset comprised 38 French individuals which represented two different haplotypes. One haplotype was identical to a 300 haplotype found in SA1 (i.e. hap_12_2) and the other haplotype was only found in France but highly similar to haplotypes found in SA6 (i.e. hap_16_12; Online Resource 2). 
302 MtDNA haplotype diversity for each marker was low within the French population $(\mathrm{Hd} \leq 0.251$,

303 Table 1). Pairwise Fst value based on $16 \mathrm{~S}$ among SA6 and France was not significant (Fst $=$

304 0.049; Online Resource 4). Haplotype diversities for nDNA ranged from 0.50 for AR up to 0.80

305 for Mastl and Prmt6 (Table 1). France comprised 13 Mastl and 16 Prmt6 alleles with seven Mastl

306 and 10 Prmt6 alleles being hitherto only found in France. nDNA allele frequencies in France

307 were most similar to those in native populations from Laingsburg in the south-western Western

308 Cape Province (SA3, Fig. 3, Online Resource 4). No significant difference was observed when

309 comparing nDNA allele frequencies among individuals representing the two different

310 mitochondrial groups $(F s t=0 ; \mathrm{p}=0.421)$, however sample sizes were low i.e. 49 and 8

311 individuals representing northern South Africa-Rooikrantz Dam mtDNA (SA5-SA6) and south-

312 western Cape mtDNA (SA1-SA2) respectively. In comparison with the native geographic

313 regions, mean nucleotide diversity across all loci in France was higher $(\pi=0.009 \pm 0.008$ versus

$314 \pi=0.0039 \pm 0.0035)$ while French haplotype diversity across all loci was comparable $(\mathrm{Hd}=$

$3150.528 \pm 0.287$ versus $\mathrm{Hd}=0.558 \pm 0.323)$.

316 Sicily

317 The Sicilian individuals were identical to native individuals from SA1 for Cytb and from SA1-

318 SA3 for 16S (Fig. 1). Only one concatenated Cytb-16S haplotype was found which was unique

319 to Sicily and highly similar to haplotypes found in FR, PT and SA1. Sicilian AR and Prmt6

320 alleles were identical to alleles occurring in the native range regions SA1-SA3. Cytb and 16S

321 sequences of Sicilian individuals sampled by Lillo et al. (2013) were not included in the current

322 analyses as they involved different gene regions. However, the mtDNA sequences in the present

323 study were identical to those of Lillo et al. (2013) in the overlapping gene regions (Cytb: $\sim 242$

324 bp, 16S: $374 \mathrm{bp})$.

\section{Discussion}

326 Since the 1930's, X. laevis has successfully invaded extensive areas worldwide particularly due 327 to its popularity for laboratory use and pet trade (Tinsley, Loumont \& Kobel, 1996; Gurdon \&

328 Hopwood, 2000; Lobos \& Measey, 2002; Crayon, 2005; Faraone et al., 2008; Measey et al., 329 2012; Herrel \& Van Der Meijden, 2014). Reconstructing the invasion history of $X$. laevis is 
330 pivotal to understand the invasion biology and range dynamics of this species and as such, might 331 be critical for developing future management strategies (Sakai et al., 2001; Lee \& Gelembiuk, 332 2008; Prentis et al., 2009). The identification of source populations is particularly relevant when 333 there is extensive population differentiation within the native range because, as well phenotypic 334 as genotypic traits of colonizing individuals might influence the invasion process (Sakai et al., 335 2001; Lee \& Gelembiuk, 2008). Here, the origin of invasive French and Portuguese X. laevis 336 specimens was investigated using DNA sequence data.

337 The genetic diversity of the invasive Portuguese populations was lower than across the native 338 range of $X$. laevis in South Africa, but the Portuguese sequences were very similar or even 339 identical to those of native individuals from the south-western Cape region in South Africa. This 340 suggest (1) that the Portuguese populations may be derived from the latter and (2) that the 341 Portuguese population derives from a single colonization event involving a small number of 342 individuals, most likely stemming from one and the same source population in the south-western 343 Cape region. This is in line with what one would expect from the historical data which attributes 344 the introduction of $X$. laevis in Oeiras (Portugal) to a single accidental flood of a basement of a research institute in 1979 (Rebelo et al., 2010). Analogous to the Portuguese samples, the identical sequences shared by the Sicilian (Lillo et. al. 2013), Chilean (Lobos et al., 2014) and south-western Cape populations samples support the idea that $X$. laevis was imported in Sicily and Chile from wild populations in the south-western Western Cape Province. Indeed, the export of $X$. laevis from the Western Cape Province is well documented, especially between 1940 and 1974 when there was only one official supplier in South Africa, i.e. Jonkershoek Fish Hatchery (Weldon, De Villiers \& Du Preez, 2007). In contrast to the $X$. laevis colonization in Portugal, two distinct and divergent mtDNA lineages were detected in France. These lineages were related to two geographically non-overlapping native regions in South Africa. A majority of the French individuals possessed mtDNA highly similar or identical to a phylogeographic lineage from northern South Africa and Rooikrantz Dam (SA5-SA6, further referred to as the northern lineage). The other French individuals had mtDNA identical to native individuals from the south-western Cape (SA1-SA2). Haplotype and sequence diversity in the French population were relatively high and comparable to those in native South African regions. The mtDNA data thus suggest that two distinct phylogeographic lineages i.e. south-western Cape and northern lineage, contributed to the invasion of $X$. laevis in 
361 France. Although the nDNA data are consistent with this suggestion, they solely indicate the

362 Laingsburg region (SA3) and the south-western Cape (SA1-SA2) as possible source areas of the

363 French nDNA alleles. This might be explained by either a scenario of a single South African

364 source area where south-western and northern lineages admix or a scenario in which France was

365 invaded by individuals from several distinct South African source areas followed by admixture

366 of the colonizing animals. In the case of the first scenario, the most likely source population

367 based upon the nDNA data would be the Laingsburg region which is considered as an admixture

368 zone among the south-western Cape regions SA1-SA2 and the Beaufort West region SA4 (Du

369 Preez et al., 2009; Furman et al., 2015). However, individuals from Laingsburg do not show

$370 \mathrm{mtDNA}$ of the northern populations. Hence, the occurrence of the main mitochondrial alleles

371 (Cytb: hap_16; 16S: hap_12) in French individuals cannot be explained by this scenario.

372 Conversely, historical data supports the second scenario in which the X. laevis invasion in France

373 stems from different source areas as animal suppliers are known from both the south-western

374 Western Cape province and the Eastern Cape Province (Port Elizabeth)( L. van Sittert and J.

375 Measey, unpublished data). Unfortunately, information concerning export from the latter region

376 is limited. In contrast, there is some export data from the Western Cape province in the period

377 that the French breeding facility was active (1950-1996) (Weldon, De Villiers \& Du Preez,

378 2007). Until 1974, there was one official animal supplier i.e. Jonkershoek Fish Hatchery.

379 Subsequently, trading was left to private enterprises for which export and collection information

380 is hitherto unknown. Yet, since 1990, permits were licenced to four South African animal

381 suppliers restricting the collection of $X$. laevis to man-made water bodies (Weldon, De Villiers \&

382 Du Preez, 2007). Around the same time, in 1989, the ownership of the French breeding facility

383 changed (Measey et al., 2012). Taking all these circumstances together, it seems likely that

384 during its 56 years of existence, the French breeding facility might have imported $X$. laevis

385 repeatedly from different South African sources. Moreover, it seems not unlikely that secondary

386 trading occurred within Europe or even worldwide e.g. among commercial breeding facilities

387 and/or research institutes.

388 To the best of our knowledge, the French $X$. laevis population is the first example in which two

389 geographically non-overlapping phylogenetic lineages participated in a X. laevis invasion. As

390 mentioned previously, two distinct mtDNA lineages, related to on the one hand the northern

391 regions of South Africa and on the other hand the southwestern Cape regions, are present in the 
392 French population. However, no population structure could be found in the invasive French

393 populations based on $\mathrm{nDNA}$. In contrast, within the native South African range these mtDNA

394 lineages are significantly divergent based on nDNA. The latter observation suggests a potential

395 role for ongoing admixture within the invasive French population. Likewise, admixture might

396 have occurred within breeding facilities among specimens from different source populations

397 preceding the French invasion. The combination of genetic variation from multiple

398 phylogeographic lineages might explain the high level of genetic diversity within France, which

399 was comparable to, or even higher than, the diversity observed in native regions. An increase in

400 genetic diversity within invasive population relative to native populations due to multiple

401 introductions of genetically divergent source populations has also been demonstrated in

402 invasions of other organisms elsewhere (Novak \& Mack, 1993; Kolbe et al., 2004, 2008;

403 Lavergne \& Molofsky, 2007). Moreover, intraspecific admixture among previously isolated

404 multiple divergent genetic lineages is often suggested to play an important role in driving the

405 success of colonising populations (Sakai et al., 2001; Lavergne \& Molofsky, 2007; Kolbe et al.,

406 2008; Lee \& Gelembiuk, 2008; Rius \& Darling, 2014). Yet, a species’ invasiveness is not only

407 function of the amount of genetic variation, but even more importantly of the nature of adaptive

408 genetic variation (Dlugosch et al., 2015). Concerning X. laevis, it is clear that single introduction

409 events even with low levels of genetic diversity have proven to be highly successful in invading

410 non-native areas such as Chile and Sicily. However, in order to predict the species' potential

411 range expansion the intraspecific variation should be taking into account (Pearman et al., 2010;

412 D’Amen, Zimmermann \& Pearman, 2013), especially for the French population, in which two

413 genetically distinct and environmentally divergent South African phylogeographic lineages have

414 contributed to the invasion. Hence, the French population offers a study system for investigating

415 the extent to which the combination of genetic variation from divergent phylogeographic

416 lineages might have influenced the French invasion and/or might influence its future range

417 expansion. In sum, the genetic structure of $X$. laevis in its native South African range allowed us

418 to investigate the geographic origins of invasive $X$. laevis populations in France and Portugal.

419 The current analyses showed that native phylogeographic lineages are not equally represented in

420 invasive European X. laevis populations.

\section{Acknowledgements}


422 This work was conducted in the contexts of the Biodiversa project BR/132/A1/INVAXEN-BE

423 "Invasive biology of Xenopus laevis in Europe: ecology, impact and predictive models" and of 424 the BELSPO-IUAP project P7/04 "SPEEDY: SPatial and environmental determinants of Eco425 Evolutionary DYnamics: anthropogenic environments as a model" and FWO research 426 community W0.009.11N "Belgian Network for DNA Barcoding”, coordinated by the "Joint 427 Experimental Molecular Unit (JEMU)" at RBINS. JM would like to thank the DST-NRF Centre 428 of Excellence for Invasion Biology for support. We gratefully thank Francesco Lillo, François 429 Lefebvre, Jean Secondi, Mohlamatsane Mokhatla and Lubabalo Mofu for their aid in sampling 430 Xenopus specimens. 
431

432

433

434

435

436

437

438

439

440

441

442

443

444

445

446

447

448

449

450

451

452

453

454

455

456

457

458

459

460

461

462

463

464

465

466

467

468

469

470

471

\section{References}

Berger L, Speare R, Daszak P, Green DE, Cunningham AA, Goggin CL, Slocombe R, Ragan MA, Hyatt AD, McDonald KR, Hines HB, Lips KR, Marantelli G, Parkes H. 1998. Chytridiomycosis causes amphibian mortality associated with population declines in the rain forests of Australia and Central America. Proceedings of the National Academy of Sciences 95:9031-9036. DOI:10.1073/pnas.95.15.9031.

Bewick AJ, Anderson DW, Evans BJ. 2011. Evolution of the closely related, sex-related genes DM-W and DMRT1 in African clawed frogs (Xenopus). Evolution 65:698-712. DOI:10.1111/j.1558-5646.2010.01163.x.

Crawford AJ, Lips KR, Bermingham E. 2010. Epidemic disease decimates amphibian abundance, species diversity, and evolutionary history in the highlands of central Panama. Proceedings of the National Academy of Sciences of the United States of America 107:13777-82. DOI:10.1073/pnas.0914115107.

Crayon J. 2005. Species account: Xenopus laevis. In: Lannoo MJ ed. Amphibian declines: The conservation status of United States species. Berkeley: University of California Press., 522525.

D'Amen M, Zimmermann NE, Pearman PB. 2013. Conservation of phylogeographic lineages under climate change. Global Ecology and Biogeography 22:93-104. DOI:10.1111/j.14668238.2012.00774.x.

Daudin FM. 1802. Histoire naturelle des rainettes, des grenouilles et des crapauds. Paris: Imprimerie de Bertrandet: Chez Levrault.

Dlugosch KM, Anderson SR, Braasch J, Cang FA, Gillette HD. 2015. The devil is in the details: genetic variation in introduced populations and its contributions to invasion. Molecular Ecology 24:2095-2111. DOI:10.1111/mec.13183.

Dlugosch KM, Parker IM. 2008. Founding events in species invasions: genetic variation, adaptive evolution, and the role of multiple introductions. Molecular Ecology 17:431-449. DOI:10.1111/j.1365-294X.2007.03538.x.

Evans BJ, Brown RM, McGuire JA, Supriatna J, Andayani N, Diesmos A, Iskandar D, Melnick DJ, Cannatella DC. 2003. Phylogenetics of fanged frogs: testing biogeographical hypotheses at the interface of the Asian and Australian faunal zones. Systematic Biology 52:794-819. DOI:10.1080/10635150390251063.

Excoffier L, Lischer HEL. 2010. Arlequin suite ver 3.5: a new series of programs to perform population genetics analyses under Linux and Windows. Molecular Ecology Resources 10:564-7. DOI:10.1111/j.1755-0998.2010.02847.x.

Faraone FP, Lillo F, Giacalone G, Lo Valvo M. 2008. The large invasive population of Xenopus laevis in Sicily, Italy. Amphibia-Reptilia 29:405-412. DOI:10.1163/156853808785112075.

Fouquet A. 2001. Des clandestins aquatiques. Zamenis 6:10-11.

Fouquet A, Measey GJ. 2006. Plotting the course of an African clawed frog invasion in Western France. Animal Biology 56:95-102. DOI:10.1163/157075606775904722.

Furman BLS, Bewick AJ, Harrison TL, Greenbaum E, Gvoždík V, Kusamba C, Evans BJ. 2015. Pan-African phylogeography of a model organism, the African clawed frog "Xenopus 
472

473

474

475

476

477

478

479

480

481

482

483

484

485

486

487

488

489

490

491

492

493

494

495

496

497

498

499

500

501

502

503

504

505

506

507

508

509

510

511

512

laevis". Molecular Ecology 24:909-25. DOI:10.1111/mec.13076.

Grab S. 2010. Drakensberg Escarpment: Mountains of geomorphic diversity. In: Migon P ed. Geomorphological landscapes of the world. Springer Dordrecht Heidelberg London New York, 133-142.

Grohovaz GS, Harley E, Fabian B. 1996. Significant mitochondrial DNA sequence divergence in natural populations of Xenopus laevis ( Pipidae ) from Southern Africa. Herpetologica $52: 247-253$.

Gurdon JB, Hopwood N. 2000. The introduction of Xenopus laevis into developmental biology: of empire, pregnancy testing and ribosomal genes. International Journal of Developmental Biology 44:43-50.

Herrel A, Van Der Meijden A. 2014. An analysis of the live reptile and amphibian trade in the USA compared to the global trade in endangered species. Herpetological Journal 24:103110.

Hudson RR, Kaplan NL. 1985. Statistical properties of the number of recombination events in the history of a sample of DNA sequences. Genetics 111:147-164.

Kessing BD, Croom H, Martin A, McIntosh C, McMillan WO, Palumbi S. 1989. The simple fool's guide to PCR. Department of Zoology, University of Hawaii, Honolulu.

Kolbe JJ, Glor RE, Rodríguez Schettino L, Lara AC, Larson A, Losos JB. 2004. Genetic variation increases during biological invasion by a Cuban lizard. Nature 431:177-181. DOI:10.1038/nature02807.

Kolbe JJ, Larson A, Losos JB, de Queiroz K. 2008. Admixture determines genetic diversity and population differentiation in the biological invasion of a lizard species. Biology Letters 4:434-437. DOI:10.1098/rsbl.2008.0205.

Lafferty KD, Page CJ. 1997. Predation on the endangered tide-water goby, Eucyclogobius newberryi, by the introduced African clawed frog, Xenopus laevis, with notes on the frog's parasites. Copeia 3:589-592. DOI:10.2307/1447564.

Lavergne S, Molofsky J. 2007. Increased genetic variation and evolutionary potential drive the success of an invasive grass. Proceedings of the National Academy of Sciences of the United States of America 104:3883-3888. DOI:10.1073/pnas.0607324104.

Lee CE. 2002. Evolutionary genetics of invasive species. Trends in Ecology \& Evolution 17:386-391. DOI:http://dx.doi.org/10.1016/S0169-5347(02)02554-5.

Lee CE, Gelembiuk GW. 2008. Evolutionary origins of invasive populations. Evolutionary Applications 1:427-448. DOI:10.1111/j.1752-4571.2008.00039.x.

Librado P, Rozas J. 2009. DnaSP v5: A software for comprehensive analysis of DNA polymorphism data. Bioinformatics 25:1451-1452. DOI:10.1093/bioinformatics/btp187.

Lillo F, Marrone F, Sicilia A, Castelli G, Zava B. 2005. An invasive population of Xenopus laevis (Daudin, 1802) in Italy. Herpetozoa 18:63-64.

Lillo F, Dufresnes C, Faraone FP, Lo Valvo M, Stöck M. 2013. Identification and potential origin of invasive clawed frogs Xenopus (Anura: Pipidae) in Sicily based on mitochondrial and nuclear DNA. Italian Journal of Zoology 80:566-573.

DOI:10.1080/11250003.2013.847502. 
513

Lillo F, Faraone FP, Lo Valvo M. 2010. Can the introduction of Xenopus laevis affect native amphibian populations? Reduction of reproductive occurrence in presence of the invasive species. Biological Invasions 13:1533-1541. DOI:10.1007/s10530-010-9911-8.

Lips KR, Brem F, Brenes R, Reeve JD, Alford RA, Voyles J, Carey C, Livo L, Pessier AP, Collins JP. 2006. Emerging infectious disease and the loss of biodiversity in a Neotropical amphibian community. Proceedings of the National Academy of Sciences of the United States of America 103:3165-70. DOI:10.1073/pnas.0506889103.

Lobos G, Mendez M a., Cattan P, Jaksic F. 2014. Low genetic diversity of the successful invasive African clawed frog Xenopus laevis (Pipidae) in Chile. Studies on Neotropical Fauna and Environment 49:50-60. DOI:10.1080/01650521.2014.912865.

Lobos G, Measey GJ. 2002. Invasive populations of Xenopus laevis (Daudin) in Chile. Herpetological Journal 12:163-168.

Mardulyn P. 2012. Trees and/or networks to display intraspecific DNA sequence variation? Molecular Ecology 21:3385-3390. DOI:10.1111/j.1365-294X.2012.05622.x.

Measey GJ. 2004. Species account: Xenopus laevis . In: Minter LR, Burger M, Harrison JA, Braack HH, Bishop PJ eds. Atlas and Red Data book of the Frogs of South Africa, Lesotho and Swaziland. Washington DC: Smithsonian Institution Press, 266-267.

Measey GJ, Rödder D, Green SL, Kobayashi R, Lillo F, Lobos G, Rebelo R, Thirion JM. 2012. Ongoing invasions of the African clawed frog, Xenopus laevis: A global review. Biological Invasions 14:2255-2270. DOI:10.1007/s10530-012-0227-8.

Measey GJ, Vimercati G, De Villiers FA, Mokhatla MM, Davies SJ, Edwards S, Altwegg R. 2015. Frog eat frog: exploring variables influencing anurophagy. PeerJ 3:e1204. DOI:10.7717/peerj.1204.

Measey GJ, Channing A. 2003. Phylogeography of the genus Xenopus in southern Africa. Amphibia-Reptilia 24:321-330. DOI:10.1163/156853803322440781.

Nixon KC. 1999. The Parsimony Ratchet, a New Method for Rapid Parsimony Analysis. Cladistics 15:407-414. DOI:10.1111/j.1096-0031.1999.tb00277.x.

Novak S, Mack R. 1993. Genetic variation in Bromus tectorum (Poaceae): comparison between native and introduced populations. Heredity 71:167-176. DOI:10.1038/hdy.1993.121.

Pearman PB, D'Amen M, Graham CH, Thuiller W, Zimmermann NE. 2010. Within-taxon niche structure: Niche conservatism, divergence and predicted effects of climate change. Ecography 33:990-1003. DOI:10.1111/j.1600-0587.2010.06443.x.

Peralta-García A, Valdez-Villavicencio JH, Galina-Tessaro P. 2014. African clawed frog ( Xenopus laevis ) in Baja California : a confirmed population and possible ongoing invasion in Mexican watersheds. The Southwestern Naturalist 59:431-434. DOI:http://dx.doi.org/10.1894/NBF-12.1.

Posada D. 2008. jModelTest: phylogenetic model averaging. Molecular Biology and Evolution 25:1253-1256. DOI:10.1093/molbev/msn083.

Du Preez LH, Kunene N, Hanner R, Giesy JP, Solomon KR, Hosmer A, Van Der Kraak GJ. 2009. Population-specific incidence of testicular ovarian follicles in Xenopus laevis from South Africa: A potential issue in endocrine testing. Aquatic Toxicology 95:10-16. 

DOI:10.1016/j.aquatox.2009.07.018.

Prentis PJ, Sigg DP, Raghu S, Dhileepan K, Pavasovic A, Lowe AJ. 2009. Understanding invasion history: genetic structure and diversity of two globally invasive plants and implications for their management. Diversity and Distributions 15:822-830. DOI:10.1111/j.1472-4642.2009.00592.x.

Rambaut A. 2006. FigTree: Tree Figure Drawing Tool v 1.4.2.

Rambaut A, Drummond AJ, Suchard M. 2013. Tracer.

Rebelo R, Amaral P, Bernardes M, Oliveira J, Pinheiro P, Leitão D. 2010. Xenopus laevis (Daudin, 1802), a new exotic amphibian in Portugal. Biological Invasions 12:3383-3387. DOI:10.1007/s10530-010-9757-0.

Rius M, Darling JA. 2014. How important is intraspecific genetic admixture to the success of colonising populations? Trends in Ecology \& Evolution 29:233-42. DOI:10.1016/j.tree.2014.02.003.

Ronquist F, Huelsenbeck JP. 2003. MrBayes 3: Bayesian phylogenetic inference under mixed models. Bioinformatics 19:1572-1574. DOI:10.1093/bioinformatics/btg180.

Sakai AK, Allendorf FW, Holt JS, Lodge DM, Molofsky J, With KA, Baughman S, Cabin RJ, Cohen JE, Ellstrand NC, Mccauley DE, O’Neil P, Parker IM, Thompson JN, Weller SG. 2001. The population biology of invasive species. Annual Review of Ecology and Systematics 32:305-332. DOI:10.1146/annurev.ecolsys.32.081501.114037.

Schliep KP. 2011. phangorn: phylogenetic analysis in R. Bioinformatics (Oxford, England) 27:592-3. DOI:10.1093/bioinformatics/btq706.

Skerratt LF, Berger L, Speare R, Cashins S, McDonald KR, Phillott AD, Hines HB, Kenyon N. 2007. Spread of Chytridiomycosis Has Caused the Rapid Global Decline and Extinction of Frogs. EcoHealth 4:125-134. DOI:10.1007/s10393-007-0093-5.

Stephens M, Donnelly P. 2003. A comparison of bayesian methods for haplotype reconstruction from population genotype data. American Journal of Human Genetics 73:1162-9. DOI:10.1086/379378.

Stephens M, Smith NJ, Donnelly P. 2001. A new statistical method for haplotype reconstruction from population data. American journal of human genetics 68:978-89. DOI:10.1086/319501.

Stöver BC, Müller KF. 2010. TreeGraph 2: combining and visualizing evidence from different phylogenetic analyses. BMC Bioinformatics 11:7. DOI:10.1186/1471-2105-11-7.

Tamura K, Stecher G, Peterson D, Filipski A, Kumar S. 2013. MEGA6: Molecular Evolutionary Genetics Analysis version 6.0. Molecular Biology and Evolution 30:2725-9. DOI:10.1093/molbev/mst197.

Team R core. 2014. R: A Language and Environment for Statistical computing.

Thompson JD, Higgins DG, Gibson TJ. 1994. CLUSTAL W: improving the sensitivity of progressive multiple sequence alignment through sequence weighting, position-specific gap penalties and weight matrix choice. Nucleic Acids Research 22:4673-4680. DOI:10.1093/nar/22.22.4673.

Tinsley RC, Loumont C, Kobel HR. 1996. Geographical distribution and ecology. In: Tinsley 
595

596

597

598

599

600

601

602

603

604

605

606

RC, Kobel HR eds. The biology of Xenopus. Oxford: Oxford University Press, 35-59.

Tinsley RC, McCoid MJ. 1996. Feral populations of Xenopus outside Africa. In: Tinsley RC, Kobel HR eds. The biology of Xenopus. Oxford: Oxford University Press, 81-94.

Voyles J, Young S, Berger L, Campbell C, Voyles WF, Dinudom A, Cook D, Webb R, Alford RA, Skerratt LF, Speare R. 2009. Pathogenesis of chytridiomycosis, a cause of catastrophic amphibian declines. Science (New York, N.Y.) 326:582-5. DOI:10.1126/science.1176765.

Weldon C, du Preez LH, Hyatt AD, Muller R, Spears R. 2004. Origin of the amphibian chytrid fungus. Emerging Infectious Diseases 10:2100-5. DOI:10.3201/eid1012.030804.

Weldon C, De Villiers AL, Du Preez LH. 2007. Quantification of the trade in Xenopus laevis from South Africa, with implications for biodiversity conservation. African Journal of Herpetology 56:77-83. DOI:10.1080/21564574.2007.9635553. 


\section{Table $\mathbf{1}$ (on next page)}

Summary of diversity statistics for all loci and each population.

Statistics describing the number of nucleotides sequenced (nt), number of individuals (ind), number of different haplotypes (h), number of segregating sites (S), nucleotide diversity ( $\pi$ ) and haplotype diversity $(\mathrm{Hd})$. 


\begin{tabular}{|c|c|c|c|c|c|c|c|c|}
\hline Gene & Country & Pop & $\mathrm{nt}$ & ind & $\mathrm{h}$ & $\mathrm{S}$ & $\pi$ & $\mathrm{Hd}$ \\
\hline \multirow[t]{6}{*}{ Cytb } & France & FR & 282 & 42 & 2 & 26 & 0.0233 & 0.251 \\
\hline & Portugal & PT & 282 & 18 & 2 & 1 & 0.00105 & 0.294 \\
\hline & South Africa & SA1 & 282 & 12 & 3 & 3 & 0.00265 & 0.53 \\
\hline & & SA5 & 282 & 13 & 8 & 10 & 0.01099 & 0.91 \\
\hline & & SA6 & 282 & 6 & 2 & 1 & 0.00119 & 0.333 \\
\hline & & SA7 & 282 & 4 & 2 & 6 & 0.01429 & 0.667 \\
\hline \multirow[t]{9}{*}{$16 \mathrm{~S}$} & France & FR & 544 & 56 & 2 & 13 & 0.00598 & 0.249 \\
\hline & Portugal & PT & 544 & 16 & 1 & 0 & 0 & 0 \\
\hline & South Africa & SA1 & 544 & 23 & 2 & 1 & 0.00055 & 0.3 \\
\hline & & SA2 & 544 & 14 & 2 & 1 & 0.00026 & 0.143 \\
\hline & & SA3 & 544 & 9 & 3 & 11 & 0.00756 & 0.556 \\
\hline & & SA4 & 544 & 12 & 3 & 2 & 0.00106 & 0.53 \\
\hline & & SA5 & 544 & 13 & 3 & 2 & 0.0008 & 0.41 \\
\hline & & SA6 & 544 & 14 & 3 & 3 & 0.00079 & 0.275 \\
\hline & & SA7 & 544 & 22 & 2 & 1 & 0.00068 & 0.368 \\
\hline \multirow[t]{9}{*}{$\mathrm{AR}$} & France & FR & 294 & 58 & 2 & 2 & 0.00338 & 0.495 \\
\hline & Portugal & PT & 294 & 18 & 1 & 0 & 0 & 0 \\
\hline & South Africa & SA1 & 294 & 27 & 1 & 0 & 0 & 0 \\
\hline & & SA2 & 294 & 13 & 4 & 4 & 0.0044 & 0.582 \\
\hline & & SA3 & 294 & 18 & 2 & 2 & 0.00347 & 0.508 \\
\hline & & SA4 & 294 & 20 & 3 & 2 & 0.0014 & 0.229 \\
\hline & & SA5 & 294 & 25 & 3 & 2 & 0.00078 & 0.222 \\
\hline & & SA6 & 294 & 9 & 1 & 0 & 0 & 0 \\
\hline & & SA7 & 294 & 23 & 2 & 1 & 0.00373 & 0.043 \\
\hline \multirow[t]{9}{*}{ Mastl } & France & FR & 525 & 53 & 13 & 6 & 0.00499 & 0.804 \\
\hline & Portugal & $\mathrm{PT}$ & 525 & 18 & 2 & 5 & 0.00053 & 0.056 \\
\hline & South Africa & SA1 & 525 & 27 & 10 & 10 & 0.00609 & 0.73 \\
\hline & & SA2 & 525 & 12 & 9 & 8 & 0.00662 & 0.873 \\
\hline & & SA3 & 525 & 9 & 8 & 12 & 0.00712 & 0.895 \\
\hline & & SA4 & 525 & 13 & 8 & 9 & 0.00453 & 0.745 \\
\hline & & SA5 & 525 & 13 & 13 & 10 & 0.00452 & 0.938 \\
\hline & & SA6 & 525 & 9 & 13 & 6 & 0.00421 & 0.961 \\
\hline & & SA7 & 525 & 24 & 7 & 10 & 0.00264 & 0.543 \\
\hline \multirow[t]{9}{*}{ Prmt6 } & France & FR & 396 & 51 & 16 & 8 & 0.00679 & 0.839 \\
\hline & Portugal & PT & 396 & 18 & 4 & 3 & 0.00213 & 0.605 \\
\hline & South Africa & SA1 & 396 & 27 & 10 & 7 & 0.00375 & 0.829 \\
\hline & & SA2 & 396 & 13 & 9 & 6 & 0.00447 & 0.871 \\
\hline & & SA3 & 396 & 8 & 10 & 9 & 0.00787 & 0.942 \\
\hline & & SA4 & 396 & 12 & 7 & 7 & 0.00498 & 0.79 \\
\hline & & SA5 & 396 & 13 & 13 & 8 & 0.00679 & 0.911 \\
\hline & & SA6 & 396 & 10 & 15 & 13 & 0.00793 & 0.974 \\
\hline & & SA7 & 396 & 22 & 1 & 0 & 0 & 0 \\
\hline
\end{tabular}




\section{Figure 1 (on next page)}

Map of the native (A. South Africa) and invaded X. laevis localities (B. Portugal, C. France) surveyed in this study.

Abbreviations and colours of sampling localities (circles) refer to geographical regions that are mentioned in methods (see 'Taxon sampling'). More detailed locality information is provided in Online Resource 1. National and provincial borders of South African Provinces are visualized by solid and dashed lines respectively (A). Rivers and roads are represented by blue and grey lines ( $B$ and $C$ ). Names of main rivers (italic) and towns are shown ( $B$ and $C$ ). 


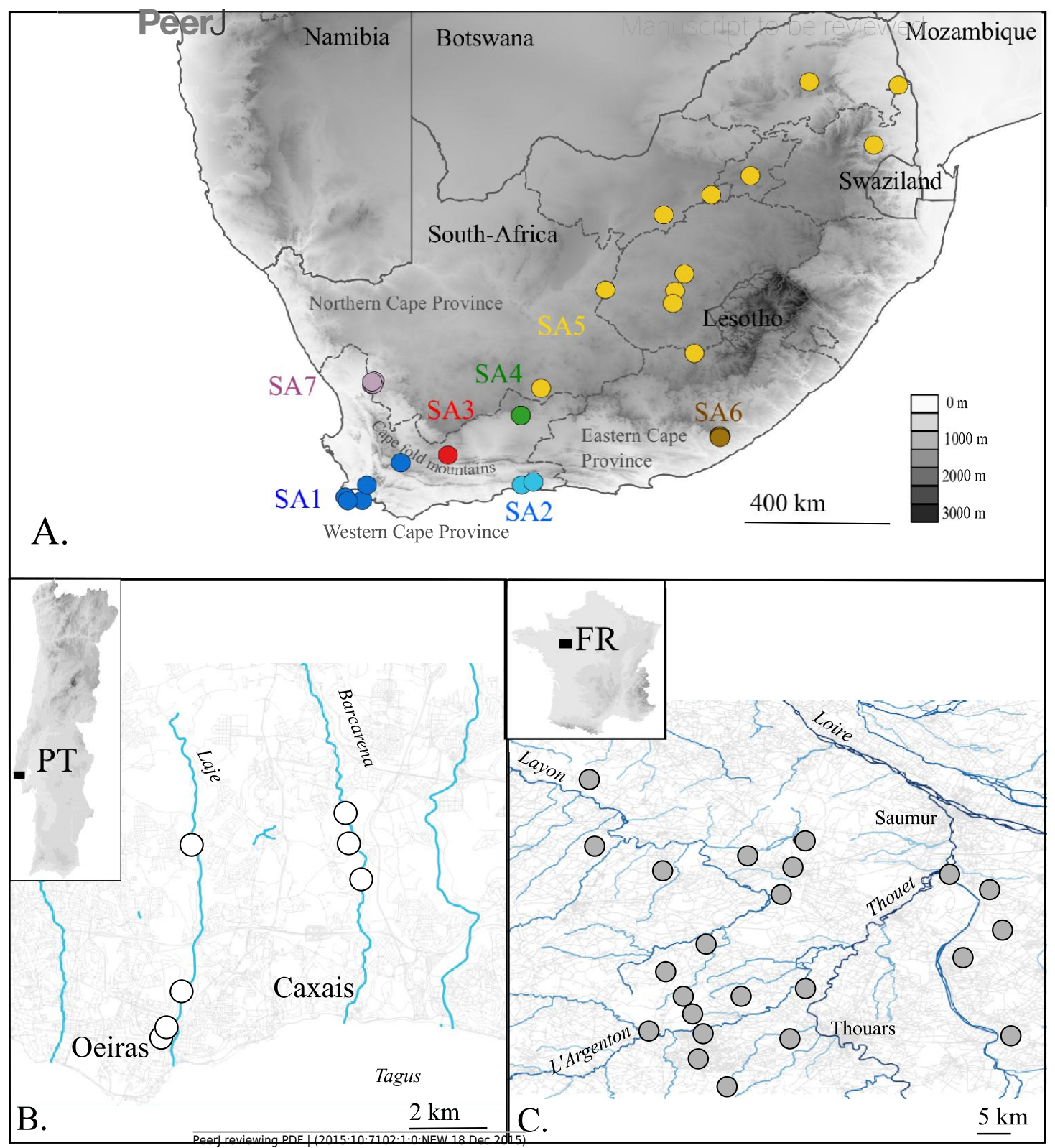


Figure 2 (on next page)

MP and BI inference based on Cytb (A) and 165 alignments (B).

Bayesian consensus trees are visualized with Posterior BI bootstrap $(B>0.70)$ and Parsimony bootstrap values. Parsimony scores (i.e. tree length) of Cytb MP tree and 16S MP tree were 83 and 47 respectively. Geographical regions where alleles have been observed are indicated in grey (abbreviations see Fig. 1 and methods). 
A.

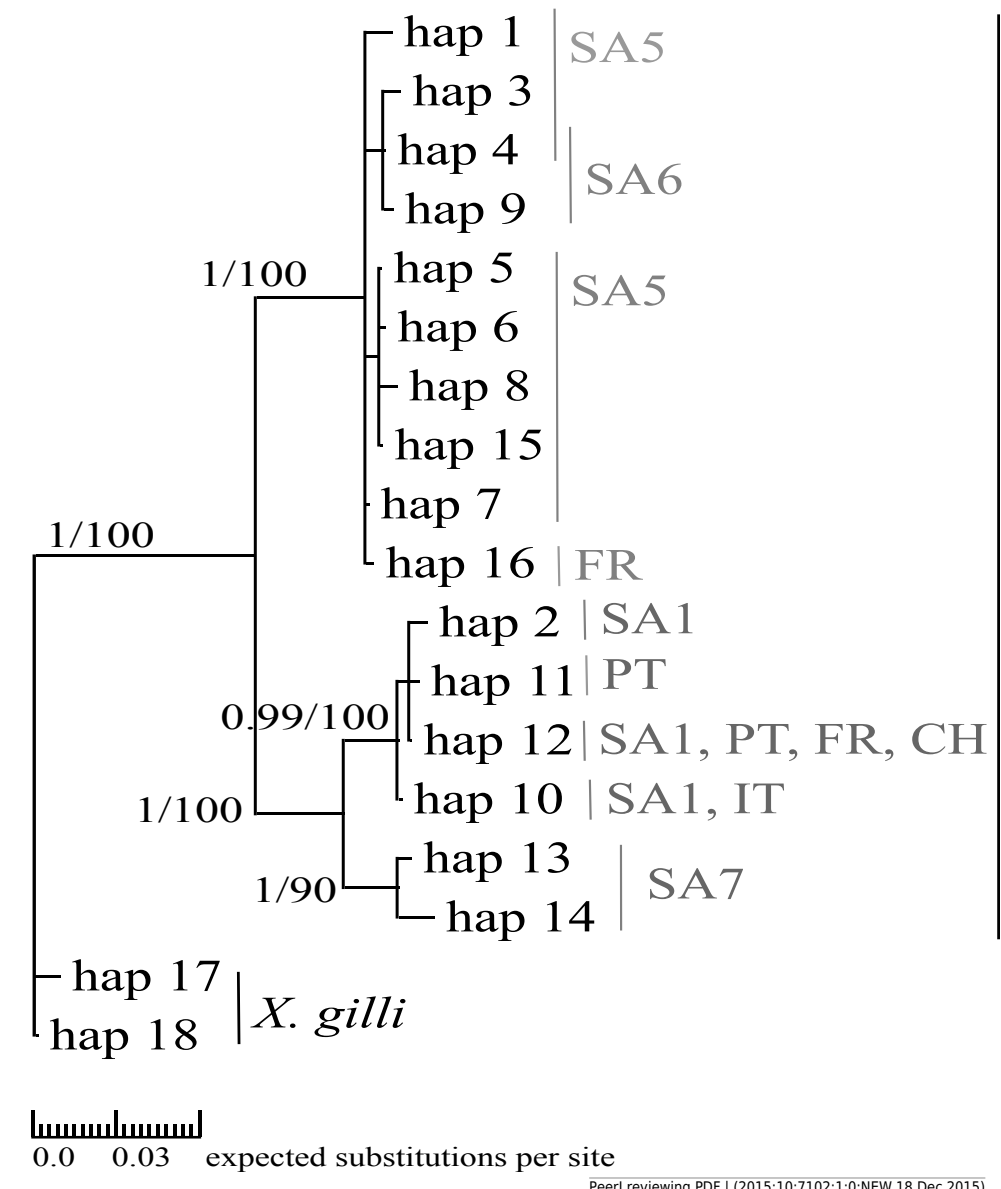

B.

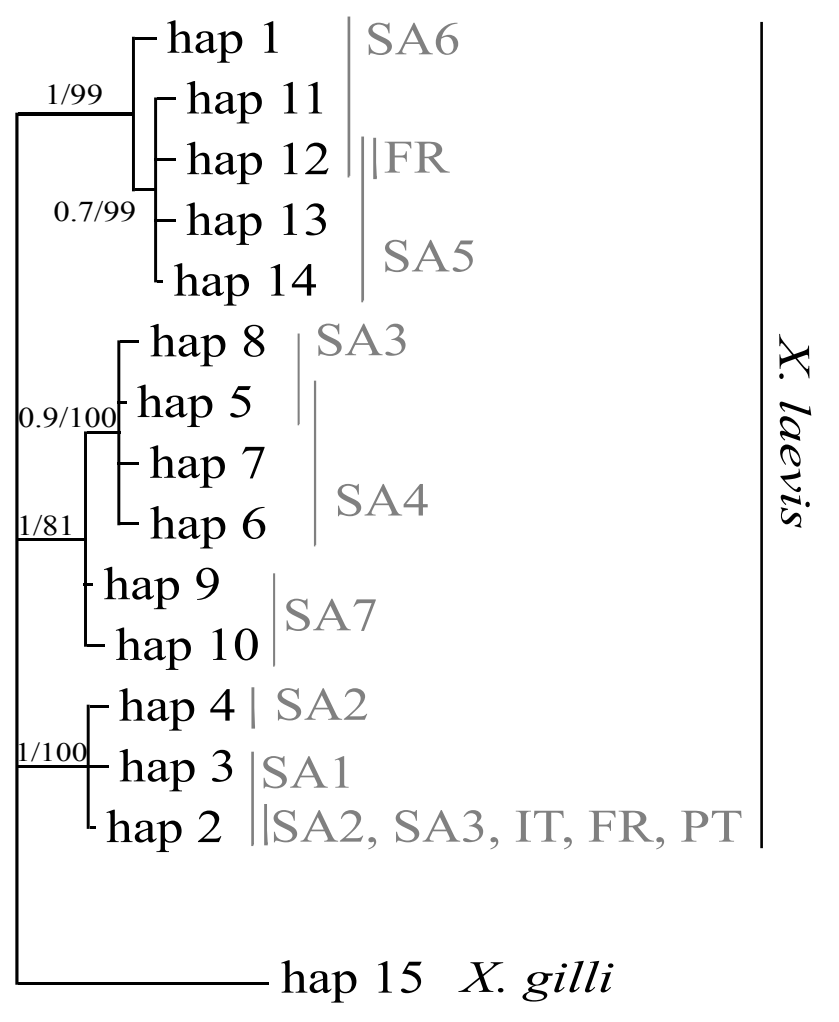

لسسسلسسسسا

$0.0 \quad 0.01$ 


\section{Figure 3 (on next page)}

Result of Principal Co-ordinate analysis of nuclear genetic variation among native (SA1SA7) and invasive French (FR) and Portuguese (PT) X. laevis populations.

PCoA of pairwise Fst values based on allele frequencies in three nuclear loci $(\mathrm{n}=180$

individuals; Online Resource 5). Abbreviations refer to geographical regions (see Fig. 1). 


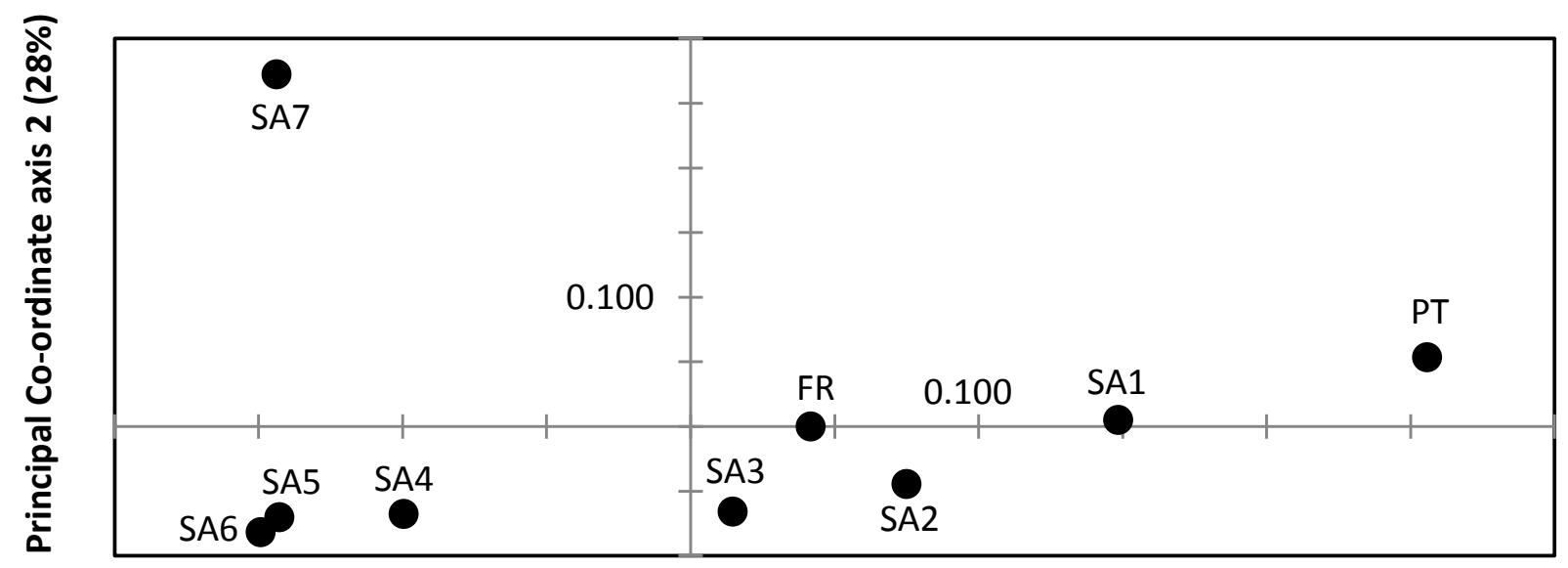

Principal Co-ordinate axis 1 (47\%) 
Figure 4 (on next page)

MJN of nuclear Prmt6 (A), AR (B) and Mastl (C) sequence data from native and invasive $X$. laevis populations.

The sizes of the circles are proportional to allele frequencies. Colours refer to native geographic and invaded regions (see legend). Small black nodes represent unsampled alleles and numbers of mutations are marked by stripes on the connecting branches 


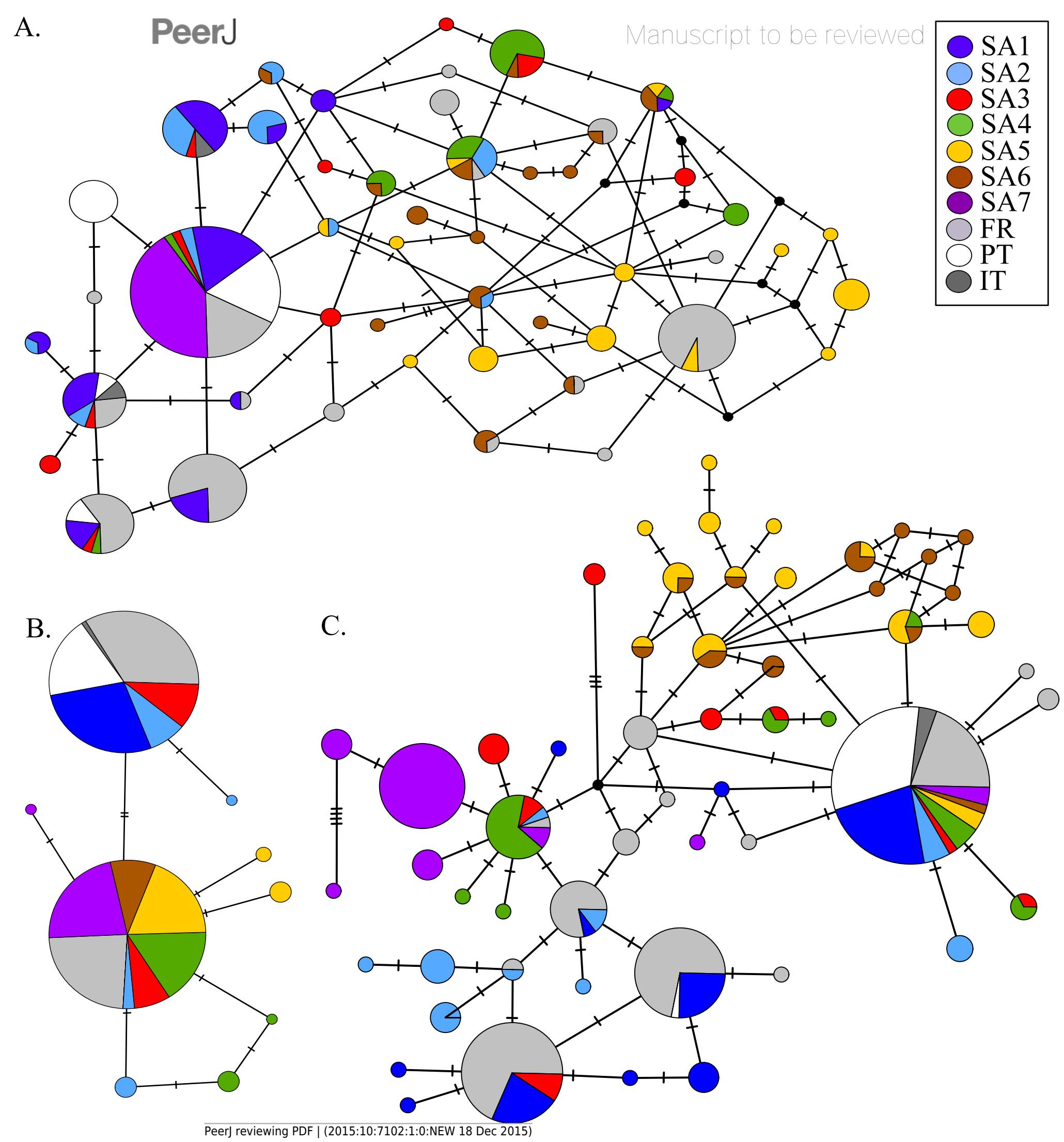

